\title{
Is the Sagittal Postural Alignment Different in Normal and Dysphonic Adult Speakers?
}

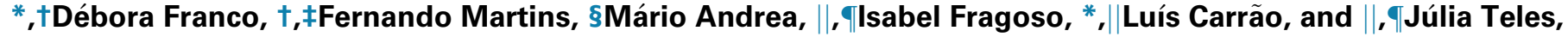 \\ *Leiria and $\dagger \ddagger \S \|$ | Lisboa, Portugal
}

\begin{abstract}
Summary: Objective. Clinical research in the field of voice disorders, in particular functional dysphonia, has suggested abnormal laryngeal posture due to muscle adaptive changes, although specific evidence regarding body posture has been lacking. The aim of our study was to verify if there were significant differences in sagittal spine alignment between normal (41 subjects) and dysphonic speakers (33 subjects).

Study Design. Cross-sectional study.

Methods. Seventy-four adults, 35 males and 39 females, were submitted to sagittal plane photographs so that spine alignment could be analyzed through the Digimizer-MedCalc Software Ltd program. Perceptual and acoustic evaluation and nasoendoscopy were used for dysphonic judgments: normal and dysphonic speakers.

Results. For thoracic length curvature (TL) and for the kyphosis index (KI), a significant effect of dysphonia was observed with mean TL and KI significantly higher for the dysphonic speakers than for the normal speakers. Concerning the TL variable, a significant effect of sex was found, in which the mean of the TL was higher for males than females. The interaction between dysphonia and sex did not have a significant effect on TL and KI variables. For the lumbar length curvature variable, a significant main effect of sex was demonstrated; there was no significant main effect of dysphonia or significant sex $\times$ dysphonia interaction.
\end{abstract}

Conclusions. Findings indicated significant differences in some sagittal spine posture measures between normal and dysphonic speakers. Postural measures can add useful information to voice assessment protocols and should be taken into account when considering particular treatment strategies.

Key Words: Voice disorders-Dysphonia-Functional dysphonia-Posture-Thoracic length curvature-Kyphosis indexLumbar length curvature.

\section{INTRODUCTION}

Clinical practice is showing that people with voice disorders or dysphonia should not be analyzed based only on the mechanism of speech production. The stomatognathic system is a combination of oral structures that develop common functions, namely breathing, chewing, swallowing, sucking, speaking, and others. "In addition to its functions, the operation" of the stomatognathic system "also depends on other systems (...), as it is not a separate unit from the rest of the body, but one which is fully integrated" (Douglas and Oncins ${ }^{1, p .111}$ ). According to the author's statements, oral communication involves a constant equilibrium, so that breathing and speaking are done efficiently. ${ }^{1}$ Clinical experience indicates that many dysphonic patients have problems related to muscles or supporting structures of the larynx. Researchers have suggested that dysphonia results from various factors: poor postural habits, hypertonicity associated with psychological states, personality, tone associated with pharyngolaryngeal reflux, neuromuscular abnormalities, and organic lesions such as nodules, polyps, cysts, and

\footnotetext{
Accepted for publication January 8, 2014.

From the *Escola Superior de Saúde, Instituto Politécnico de Leiria, Leiria, Portugal; †Centro de Linguística, Universidade de Lisboa, Lisboa, Portugal; †̦Faculdade de Letras, Universidade de Lisboa, Lisboa, Portugal; §Faculdade de Medicina, Universidade de Lisboa, Lisboa, Portugal; ||Faculdade de Motricidade Humana, Universidade de Lisboa, Lisboa, Portugal; and the $₫$ Centro Interdisciplinar de Performance Humana (CIPER), Lisboa, Portugal.

Address correspondence and reprint requests to Débora Franco, Departamento De Ciências e Tecnologias da Saúde, Escola Superior de Saúde, Instituto Politécnico de Leiria, Campus 2 - Morro do Lena - Alto do Vieiro, Apartado 4137, 2411-901 Leiria, Portugal. E-mail: debora.franco@ipleiria.pt

Journal of Voice, Vol. 28, No. 4, pp. 523.e1-523.e8

$0892-1997 / \$ 36.00$

(C) 2014 The Voice Foundation

http://dx.doi.org/10.1016/j.jvoice.2014.01.002
}

tumors. ${ }^{2,3}$ Bad posture is unhealthy because it is not balanced or efficient and, therefore, results in postural perturbations. ${ }^{4}$ It leads to muscle weakness and adaptive lengthening, degenerative changes, pain, deformity, compensation, limitation of motion, decreased vital capacity, changes in sustentative and protective physiological functions, and instability. ${ }^{5}$ The term body posture can refer to a set of positions of the body joints at a particular moment. ${ }^{6}$ Thus, a normal posture implies absence of stress, strain, opposing forces, and the existence of a harmonious pain-free relation. ${ }^{4,7}$ Body alignment must be done with minimum effort and maximum physiological and biomechanical efficiency, so that the person preserves his/her center of gravity within the base of support. ${ }^{4,8}$ A normal spine has two lordotic curves in the cephalic and caudal regions. In between these two lordotic curves exists a kyphotic curve. This curvature pattern is normal if it allows equal distribution of forces across the spine. Therefore, sagittal misalignment is an exaggeration or deficiency of normal lordosis and kyphosis.

Posture has been understood as an important component of voice quality, especially from deeper ongoing studies of functional dysphonia and more precisely with the introduction of the labels of vocal abuse/misuse syndrome or Bogart-Bacall syndrome and muscle tension dysphonia (MTD). Morrison ${ }^{2}$ began to describe the MTD process based on case studies of vocal pathology that demonstrate muscular misuse and postural alterations. MTD is the pathologic condition of excess tension in the paralaryngeal and suprahyoid muscles, which is commonly seen in young and middle-aged females. ${ }^{2,3,10,11}$ Consequently, the presence of an open posterior glottic chink, larynx elevation, and mucosal changes in the vocal folds are frequent. ${ }^{2,3,10,12}$ 
Two forms of MTD were introduced. Primary MTD occurs in the absence of concurrent organic vocal fold pathology, ${ }^{2,3,11,12}$ and secondary MTD involves the presence of an underlying organic condition. ${ }^{2,11-13}$ Angsuwarangsee and Morrison ${ }^{10}$ found that the laryngeal extrinsic muscle tension is more prominent in people with some kind of muscle misuse dysphonia than in those with other diagnosis of voice disorders. This suggests an abnormal laryngeal posture, which may have different etiologies. For example, researchers have described cervical hyperlordosis with extension of the head and kyphotic hump in the upper thoracic vertebrae as having a relation with poor laryngeal posture, increased vocal effort, and muscular tension in and around the larynx, during phonation. ${ }^{14}$ If this muscle misuse persists over time, the laryngeal muscles become persistently tense. The disorder of the laryngeal complex and persistent closure of the thyrohyoid or cricothyroid spaces or anterior positioning of the cricoid cartilage relative to the thyroid cartilage may suffer consequences as a result of all this vocal misuse. ${ }^{10,15-18}$ Therefore, posture is a current concern in the field of voice disorders. ${ }^{10,12,16,18,19}$

Posture involves constant postural adjustments, with numerous intrinsic and extrinsic factors affecting these postural strategies. Postural strategy associated with extrinsic factors is affected by the biomechanical demands necessary to maintain balance. ${ }^{20}$ Intrinsic factors include respiration and neuromuscular fatigue. $^{20,21}$ Through feedback and feedforward mechanisms, postural adjustments play a critical role in the control of postural orthostatic and even postural dynamics, which influence voice production and the ability to perform daily life activities. ${ }^{22,23}$ However, it is still necessary to find evidence on how spine posture may be associated with vocal function. ${ }^{10,12,16,18,19}$ Clinical experience indicates that some patients with dysphonia also have postural complaints, but researchers rarely express these postural problems or indicate their prevalence or objectively evaluate the spine alignment. Furthermore, quantitative evidence about causal factors of voice disorders is still insufficient, especially in the field of functional dysphonia. Our study is part of a multidimensional voice quality investigation, developed by the Universidade de Lisboa to provide further evidence on voice quality and spine posture. The purpose of this study was to verify if there were significant differences in sagittal spine alignment between normal and dysphonic speakers. Besides that, the effects of sex were also evaluated as well as sex $\times$ dysphonia interaction on sagittal spine alignment.

\section{MATERIALS AND METHODS}

\section{Subjects}

The sample consisted of 74 individuals. All subjects were aged between 20 and 50 years, spoke European Portuguese as their first language, had no functional respiratory changes, and signed informed consent forms. Subjects with musculoskeletal disease, craniofacial malformations, orthopedic trauma, spirometry examination with alterations, neurologic diseases, neck scarring from surgery, radiation therapy or trauma, and previous history of larynx surgery, were excluded from the study.
Only new patients were included to ensure that knowledge of a previous diagnosis would not bias the results. Subjects were classified into two groups on the basis of their voice quality: normal speakers and dysphonic speakers. The normal speakers group consisted of 41 subjects ( 22 males and 19 females) with a mean age of $31.02 \pm 9.54$ years. The dysphonic speakers group consisted of 33 subjects (13 males and 20 females) with a mean age of $33.36 \pm 10.94$ years.

\section{METHOD}

\section{Ethics statement}

Ethical approval to undertake this study was obtained from the Ethics Committee for Health from the Centro Hospitalar Lisboa Norte/Faculdade de Medicina, of the Universidade de Lisboa. The study was also approved by the Management Board of Hospital de Santa Maria/Centro Hospitalar Lisboa Norte. Informed consent was acquired from all participants before the examination. However, the explanations given to the participants were merely those required for informed consent thus minimizing the effects on their usual body posture, considering the importance of natural behavior during the entire proceedings.

\section{Experimental procedure}

The experimental procedure was performed in the Department of Ear, Nose, Throat, Voice and Communication Disorders, of the Hospital de Santa Maria, Faculdade de Medicina, of Universidade de Lisboa. Potential participants were initially assessed for eligibility by an interview followed by a spirometry. Next, postural evaluation and voice quality assessments were performed.

Postural evaluation. The sagittal spinal curvatures of each subject were analyzed namely thoracic length curvature (TL), kyphosis index (KI), and lumbar length curvature (LL). The KI was calculated as a ratio of the thoracic width (TW) and the TL. A sagittal photograph was taken, with the participants in an upright standing position. For the analysis, the Digimizer program (MedCalc Software Ltd, Ostend, Belgium) was used, followed by the Flexicurve method. ${ }^{24}$ The procedural methods are described in the Addendum section. Figure 1 illustrates the variables measured. According to the Greendale et $\mathrm{al}^{25}$ research, the Flexicurve KI had high intrarater and interrater reliabilities and did not differ significantly from other nonradiological kyphosis assessments. In our study, to avoid interrater reliability, all the measurements were done by a physiotherapist experienced in assessing spinal function using the Digimizer (MedCalc Software Ltd, Ostend, Belgium) and the Flexicurve method. These methods have particular advantages: (1) low cost, (2) are noninvasive and are radiation free, (3) are easy to use, (4) have short measurement time, and (5) relative robustness to variations in spine contour and deformity. ${ }^{25}$ Ten photographs were "rerated" three times, and the mean value obtained was then used. Intrarater reliability was evaluated using the intraclass correlation coefficient, more precisely, through the ICC $(3,1)$. The attained values ranged from 0.856 for KI to 0.992 for LL, indicating that the intrarater reliabilities varied from good to excellent. The standard error of measurement was also computed. The results are presented in Table 1. 


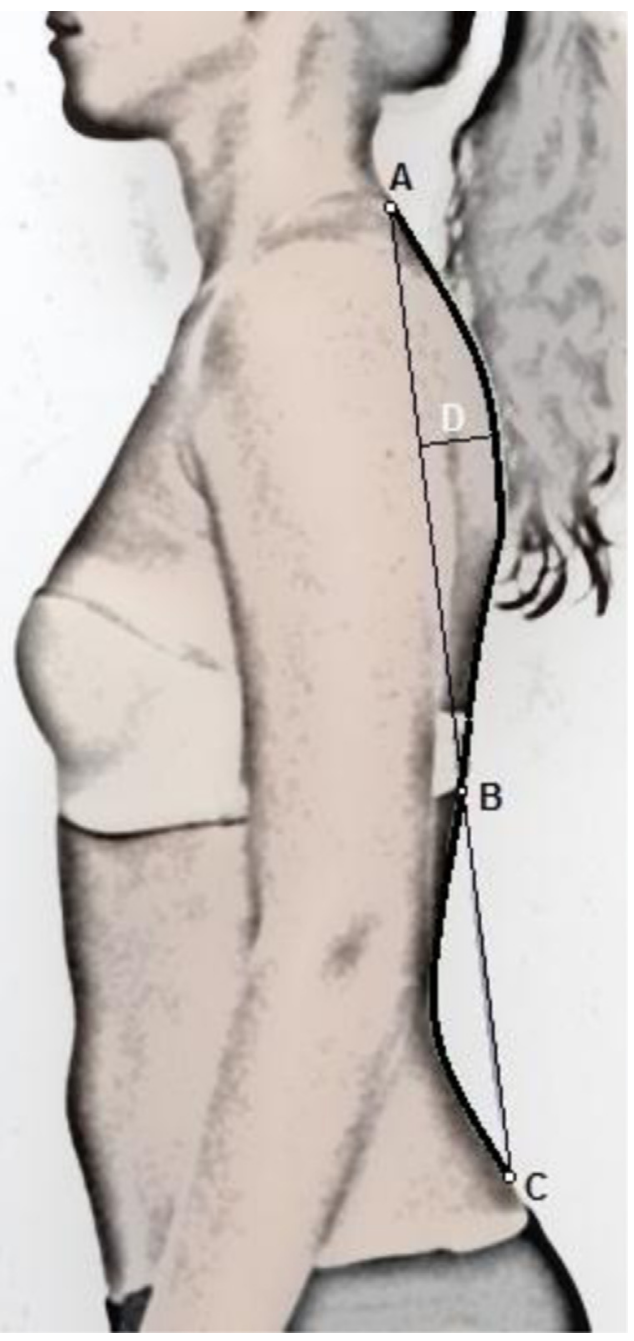

FIGURE 1. The anatomical landmarks illustrated are: C7 (A), the inflection point (B), and L5/S1 interspace (C). The spine characterization variables: $\mathrm{TL}=$ distance in centimeters between $\mathrm{A}$ and $\mathrm{B}$, $\mathrm{LL}=$ distance in centimeters between points $\mathrm{B}$ and $\mathrm{C}, \mathrm{KI}=$ thoracic width (D)/thoracic length curvature $\times 100$.

Voice quality evaluation. In this particular study, nasoendoscopy plus perceptual and acoustical evaluations were used in a complementary way. The procedural methods are included in the Addendum. In our study, subjects were classified as normal or dysphonic speakers according to the methodology described by Guimarães and Abberton. ${ }^{26}$ Specifically, a subject with vocal disorders or dysphonia was one with (1) vocal com-

TABLE 1.

Intrarater Reliability, ICC $(3,1)$, and SEM of Sagittal Spine Variables

\begin{tabular}{lcc}
\hline Sagittal Spine Variables & ICC $(95 \% \mathrm{CI})$ & SEM \\
\hline LL & $0.992(0.972-0.998)$ & 0.646 \\
TL & $0.987(0.962-0.996)$ & 1.215 \\
KI & $0.856(0.645-0.958)$ & 0.751 \\
\hline
\end{tabular}

Abbreviations: KI, kyphosis index; LL, lumbar length curvature; $\mathrm{TL}$, thoracic length curvature. plaints for more than 15 days, (2) evidence of structural lesion, and/or (3) alterations in laryngeal dynamics that were reflected perceptually and acoustically. If a speaker experienced two or more of the aforementioned conditions, he/she was classified as dysphonic. Laryngeal inspection was made by the ear, nose, and throat surgeon after a nasoendoscopic examination. The reference values of perceptive measures (grade component of the GRBAS scale ${ }^{27}$ ) and acoustic measures (fundamental frequency, jitter, intensity, shimmer, and harmonic-to-noise ratio) used to decide the diagnosis were in accordance with Hirano, ${ }^{27}$ Guimarães and Abberton, ${ }^{26}$ Behlau et al, ${ }^{28}$ Mendes and Castro. ${ }^{29}$ As reported in the literature, jitter, shimmer, and "noise" variables are the acoustic measures most commonly correlated to perceptual measures. ${ }^{30}$ Brutha et $\mathrm{al}^{31}$ reported "noise" as being the perceived acoustical quality of the dysphonic voice. Furthermore, and according to Ortega et al, ${ }^{32}$ the negative predictive value of acoustic and perceptual assessment is very high, especially if tests are used together.

\section{Statistical data analysis}

Data was analyzed with IBM SPSS Statistics v20 (SPSS Corporation, Chicago, $\mathrm{IL}^{33}$ ) and the statistical significance level was set at 5\%. Descriptive statistics measures were used to characterize the study sample: means and standard deviations (SD) for continuous variables; frequencies and percentages for categorical variables. Two-way analyses of variances (ANOVAs) were applied to evaluate the effect of dysphonia, sex, and sex $\times$ dysphonia interaction, on the mean of each dependent variable (TL, LL, and KI). The two-way ANOVA assumptions of normality and homogeneity of variance were assessed using the Shapiro-Wilk test and the Levene test, respectively.

\section{RESULTS}

The descriptive characteristics of demographic variables are summarized in Table 2, for both sexes. Some descriptive measures of sagittal spine variables (TL, LL, and KI), according to dysphonia and sex, are presented in Table 3. TL and LL variables were measured in centimeters.

Concerning the TL variable, the two-way ANOVA yielded a significant main effect of $\operatorname{sex}\left(F(1,70)=112.43, P<0.001 ; \eta_{P}^{2}\right.$ $=0.616$, large effect ${ }^{34}$ ), being the mean of TL higher for men $(M=51.15, \mathrm{SD}=5.62)$ than for women $(M=38.13$, $\mathrm{SD}=5.21$ ) (Figure 2) and a significant main effect of dysphonia $\left(F(1,70)=4.55, P=0.036 ; \eta_{P}^{2}=0.061\right.$, medium effect $\left.^{34}\right)$, being the mean of the TL higher for dysphonic speakers $(M=44.74, \mathrm{SD}=8.31)$ than for normal speakers $(M=43.92$, $\mathrm{SD}=8.67)$; there was a nonsignificant sex $\times$ dysphonia interaction $(F(1,70)=0.18, P=0.670$; power $=0.071)$.

For the LL variable, the two-way ANOVA revealed a significant main effect of $\operatorname{sex}\left(F(1,70)=31.41, P<0.001 ; \eta_{P}^{2}=0.310\right.$, large effect $\left.{ }^{34}\right)$, being the mean LL higher for women $(M=15.37$, $\mathrm{SD}=4.27)$ than for men $(M=9.14, \mathrm{SD}=5.63)$, as illustrated in Figure 2; the dysphonia $(F(1,70)=1.83, P=0.181$; obs. power $=0.266)$ and the sex $\times$ dysphonia interaction $(F(1,70)=0.18, P=0.670$; power $=0.128)$ did not have a significant effect on the mean of the LL. 
TABLE 2.

Descriptive Measures of Demographic Variables of Subjects According to Sex $(N=74)$

\begin{tabular}{|c|c|c|c|c|}
\hline Characteristics & \multicolumn{2}{|c|}{ Male } & \multicolumn{2}{|c|}{ Female } \\
\hline Sex & $35(47.30)$ & & $39(52.70)$ & \\
\hline Age $(y)$ & & $32.43(9.94)$ & & $31.74(10.52)$ \\
\hline Height (cm) & & $174.65(6.65)$ & & 158.89 (17.13) \\
\hline Mass (kg) & & $74.40(13.43)$ & & $59.78(11.66)$ \\
\hline High school & $18(51.43)$ & & $19(48.72)$ & \\
\hline College & $11(31.43)$ & & $17(43.59)$ & \\
\hline \multicolumn{5}{|l|}{ Dental characterization } \\
\hline Without alteration & $32(91.43)$ & & $28(71.79)$ & \\
\hline Orthodontic braces & $0(0.00)$ & & $3(7.69)$ & \\
\hline Orthodontic retainers & $1(2.86)$ & & $1(2.56)$ & \\
\hline
\end{tabular}

Regarding the KI, the two-way ANOVA indicated a significant main effect of dysphonia $\left(F(1,70)=4.85, P=0.031 ; \eta_{P}^{2}\right.$ $=0.065$, medium effect $\left.{ }^{34}\right)$, being the mean KI higher for dysphonic speakers $(M=15.27, \mathrm{SD}=1.85)$ than for normal speakers $(M=14.27, \mathrm{SD}=2.04)$; $\operatorname{sex}(F(1,70)=0.37$, $P=0.547$; obs. power $=0.092)$ and the sex $\times$ dysphonia interaction $(F(1,70)=0.01, P=0.921$; obs. power $=0.051) \mathrm{did}$ not have a significant effect on the mean of the KI (Figure 2).

\section{DISCUSSION}

Our findings suggested a significant effect of dysphonia on spine posture measures, between normal and dysphonic speakers. However, the comprehensive classifications systems and the criteria for sagittal spine alignment classification, particularly in respect to dysphonia, are still ambiguous and equivocal. A substantial disparity exists in the literature regarding the curvature of the thoracic and lumbar spines. ${ }^{9,35}$ Thoracic kyphosis has been reported to be in the $30^{\circ}-50^{\circ}$ range, ${ }^{9,35}$ whereas lumbar lordosis ranges from $30^{\circ}$ to $50^{\circ},{ }^{35}$ and may vary depending on the inclusion of the lumbosacral junction. ${ }^{9}$ However, a positive correlation exists between thoracic kyphosis and lumbar lordosis. ${ }^{36}$ Considering the physiological and biomechanical efficiency of the body, the analysis of sagittal spine posture is essential. Miyakoshi et $\mathrm{al}^{37}$ suggested lumbar kyphosis as a negative predictor of quality of life, and spinal mobility as a positive predictor and the most important factor. A person with an

TABLE 3.

Descriptive Measures of Sagittal Spine Variables (TL, LL, and KI) for Normal and Dysphonic Speakers, According to Sex

\begin{tabular}{|c|c|c|c|c|c|c|}
\hline Variable & \multicolumn{3}{|c|}{ Male } & \multicolumn{3}{|c|}{ Female } \\
\hline \multicolumn{7}{|l|}{$\mathrm{TL}(\mathrm{cm})$} \\
\hline Dysphonic speakers & $13(37.14)$ & $45.22 / 61.71$ & $52.49(5.05)$ & $20(51.28)$ & $30.64 / 47.23$ & $39.70(5.68)$ \\
\hline Total & $35(47.23)$ & $41.27 / 63.71$ & $51.15(5.62)$ & $39(52.70)$ & $26.33 / 47.23$ & $38.13(5.21)$ \\
\hline Dysphonic speakers & $13(37.14)$ & $0.00 * / 12.57$ & 7.54 (4.69) & $20(51.28)$ & $6.05 / 20.95$ & $15.07(4.32)$ \\
\hline Total & $35(47.23)$ & $0.00 * / 18.80$ & $9.14(5.63)$ & $39(52.70)$ & $6.50 / 22.28$ & $15.37(4.27)$ \\
\hline \multicolumn{7}{|l|}{$\mathrm{KI}$} \\
\hline Normal speakers & $22(62.86)$ & $10.85 / 17.39$ & $14.42(2.00)$ & $19(48.72)$ & $10.44 / 17.57$ & $14.09(2.14)$ \\
\hline Dysphonic speakers & $13(37.14)$ & $12.34 / 18.76$ & $15.41(1.73)$ & $20(51.28)$ & $12.50 / 19.43$ & $15.17(1.97)$ \\
\hline Total & $35(47.23)$ & $10.85 / 18.76$ & $14.79(1.94)$ & $39(52.70)$ & $10.44 / 19.43$ & $14.65(2.10)$ \\
\hline
\end{tabular}

Abbreviations: $\mathrm{KI}$, kyphosis index; $\mathrm{LL}$, lumbar length curvature; $\mathrm{TL}$, thoracic length curvature.

* The value 0.00 means that the distance between point $B$ and $C$ in Figure 1 is null, with no curvature (flat lumbar curvature) and no point of inflection. A kyphotic attitude is maintained along the entire spinal column. 

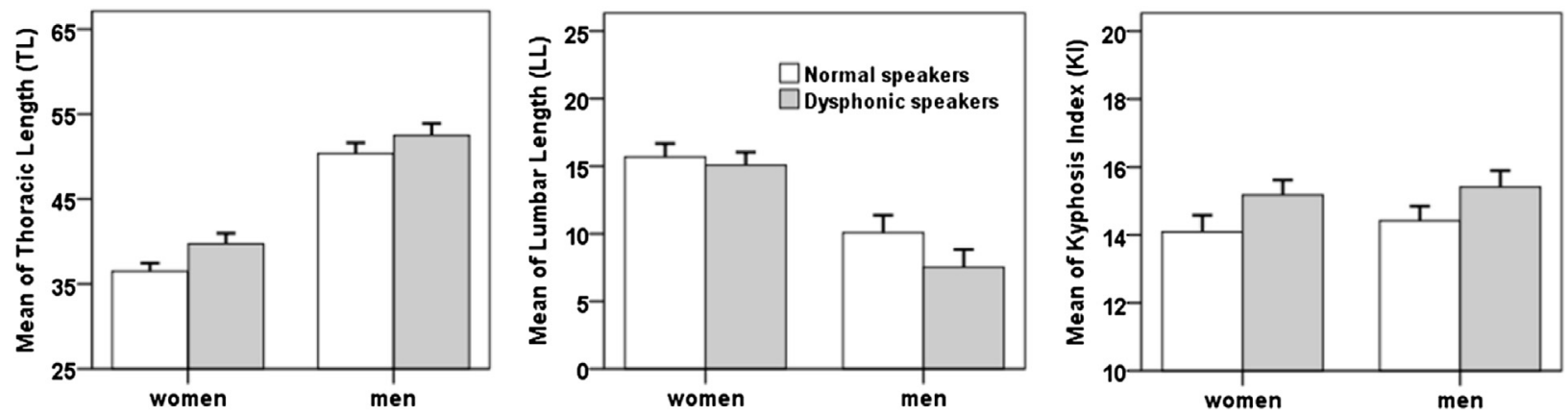

FIGURE 2. Mean and standard error of TL, LL, and KI, for normal and dysphonic speakers, according to sex. LL, lumbar length curvature; KI, kyphosis index; TL, thoracic length curvature.

angular change in a similar segment of the spine equal to that of another person may experience a different effect on the global spine due to the compensatory and interactive relationship among separate segments of the spine. ${ }^{35}$ In fact, a "proper" posture implies a perfect balance between deep extensor muscles and flexors leading the body to a maximum economy state. ${ }^{4}$ When the constant equilibrium is permanently altered, compensations develop. These compensations occur in spine posture and also in laryngeal configuration. Whether the altered spine curvatures result from (functional or organic) dysphonia or dysphonia results from altered spine curvatures is still a subject of debate. For example, in our study, we had individuals that had alterations in spine curvatures without dysphonia or vocal complaints and the inverse. Bricot ${ }^{38}$ says that $90 \%$ of the population has postural imbalance. An explanation for abnormal posture is multiplex and multifactorial. The impact of this imbalance on voice quality will depend on other interacting factors, including those already mentioned. Our results indicated that there were no differences in LL between dysphonic and normal speakers, despite the sex $\times$ dysphonia interaction. However, a significant difference was demonstrated between the two groups regarding the TL. Furthermore, there were also significant differences in KI between dysphonic and normal speakers, confirming the above results. This quantitative evidence is in accordance with the suggestions of some researchers. ${ }^{14-16,19,23,39,40}$

A deviant posture, such as posterior or anterior weight bearing, excessive lordosis, kyphosis, and/or a deviant head position, will be compensated by the neck and the laryngeal area. ${ }^{16,41}$ When we consider thoracic kyphosis, the shoulders are in a rounded forward position. ${ }^{19}$ This condition promotes the tightness of the pectoral region of the chest as well as an adaptive shortening of the abdominals and extrinsic laryngeal muscles, which can cause a loss of postural balance or a decrease of postural strategies during phonation as a result of an alteration of the body's proprioceptive scheme. ${ }^{16,19,23,39}$ Consequently, the head assumes a position that projects the eyes to a downward gaze. A horizontal gaze is facilitated by the upper cervical spine, it must hyperextend. ${ }^{18}$ This positioning of the head and neck develops a weakness in the muscles of the anterior neck (suprahyoid and infrahyoid muscles) and neck retractors, with adaptive shortening of the suboccipital group. ${ }^{18,19}$ Hulse $^{42}$ also described the relationship between cervical problems and increased tension in the larynx, which re- sults in vocal disorders. According to Arboleda and Frederick, ${ }^{19}$ one of the consequences of voice production is a narrowing of the pharynx, which can be expected to negatively impact vocal resonance. The authors ${ }^{16,23}$ stated that clinical evidence exists of the presence of hypertonicity of the extrinsic laryngeal muscles, of posterior weight bearing, and of forward positioning of the head in severe dysphonia.

In the kyphotic posture, both the intercostals and the abdominal muscles assume adapted shortened positions with impact in the lung volume for inspiration, by restricting both descent of the diaphragm and lateral expansion of the ribs. Airflow for voicing is compromised under this condition and may result in vocal fatigue and difficulty in projecting the voice. ${ }^{19}$ According to Estenne et $\mathrm{al}^{43}$ the activity of thoracic and abdominal muscles in phonation appears to affect postural control. Therefore, many of the changes in the volume of the voice are caused by active emptying of the rib cage, performed by the contraction of the triangularis sterni and the abdominal muscles, needed to optimize the movement of inspiration of the diaphragm, which rapidly contracts during vocal production to fill the respiratory system between phrases. ${ }^{23,43}$ During loud speech production and during speech produced at low lung volumes, in an upright position, the oblique abdominal muscles are actively contracted. ${ }^{44,45}$ Moreover, the active rib cage enlargement that occurs during prephonatory posturing is not a passive response to abdominal compression. $^{23,46}$ Furthermore, misalignment of the head position, including an increase in lumbar lordosis with adaptive head elevation, determines an inflexible respiratory pattern which results in compression of the vocal tract. ${ }^{26,47}$

Finally, and as previously shown, our results point to a higher mean TL for the dysphonic speakers group in comparison with the normal speakers group after controlling for sex differences. The same difference is observed in the mean of the KI. The results are in accordance and can support other research of the disturbed vocal fold behavior spectrum, in particular MTD. $3,10,16,18$ Morrison and Rammage ${ }^{40}$ pointed out essentially four internal factors that affect phonation: deviant body posture and muscle misuse, vocal behaviors, emotional factors, and gastroesophageal reflux. To these factors, researchers have added the asymmetric tension of the head and shoulders, increasing cervical lordosis, which have direct consequences in phonation. ${ }^{40}$ In fact, Angsuwarangsee and Morrison ${ }^{10}$ admitted that muscle misuse dysphonia was probably the 
most frequent cause of chronic functional dysphonia. Van Houtte et $\mathrm{al}^{3}$ suggested three distinct categories that catalog the etiologic factors of MTD: personality and psychological factors, vocal misuse/abuse, and compensation of an underlying disease. Consequently, the larynx muscles become hypertensed because they try to find a new point of balance. ${ }^{3}$

Finally, we present some issues of importance, which can be taken into account in future studies. First, it may be useful to have a clear and precise definition of different spine curvature types based on the length and balance of the spine curvature, to distinguish between normal and pathologic spine postures. Second, in spite of researchers like Greendale et $\mathrm{al}^{25}$ that argue the use of nonradiological spine assessments in the clinical routine based on their several advantages, other tools should be used in combination with visual assessment to improve the quality of the spinal posture examination. ${ }^{25,48}$ Third, longitudinal studies should be developed to provide information about the causeeffect relationship between sagittal spine posture and dysphonia, taking into account knowledge of two aspects: (1) the magnitude of changes in spine curvature measures that can cause dysphonia and (2) the magnitude of alterations in vocal dynamics and in the larynx that can cause changes in the sagittal spine posture.

\section{CONCLUSION}

The findings of this study indicate that mean TL and KI values may be significantly higher for normal versus dysphonic speakers. In contrast, there were no significant differences in mean LL between normal and dysphonic groups. This study compared, for the first time, the length of the curvature and balance of the entire spine curvature alignment based on vocal quality. We demonstrated important biomarkers in voice disorders. Spine posture must be taken into special account, especially when other dysphonic risk factors are observable. Therefore, we believe that postural measures may be useful additions to voice assessment protocols and should be taken into account when considering particular treatment strategies. Only through an integral and comprehensive vision of the human being can we begin to solve vocal problems.

\section{Acknowledgments}

We want to express our deep appreciation to everyone who assisted us at the various levels of this study, for their professionalism, diligence and time, especially: The Department of ENT, Voice and Communication Disorders, of the Hospital Santa Maria, Faculdade de Medicina of Universidade de Lisboa.

\section{REFERENCES}

1. Douglas CR, Oncins M. Fundamentos fisiológicos para motricidad orofacial. In: Susanibar F, Parra D, Dioses A, eds. Motricidad Orofacial-Fundamentos Basados en Praticas. Madrid, Spain: Editorial EOS; 2013:111-139.

2. Morrison M. Pattern recognition in muscle misuse voice disorders: how I do it. J Voice. 1997;11:108-114.

3. Van Houtte E, Van Lierde K, Clayes S. Pathophysiology and treatment of muscle tension dysphonia: a review of the current knowledge. $J$ Voice. 2011;25:202-207.

4. Mosculino JE. Cinesiologia, o Sistema do Esqueleto e a Função Muscular. Loures, Portugal: Lusodidacta; 2008
5. Jacques HJA. Alunos Sinistros $\times$ Carteiras Escolares: um Estudo com Assimetrias Posturais [unpublished dissertation]. Lisboa, Portugal: Faculdade de Motricidade Humana; 2002.

6. Magee DJ. Avaliação postural. In: Magee DJ, ed. Disfunção Musculoesquelética. 3rd ed. São Paulo, Brazil: Manole; 2002:105-157.

7. Yip CHT, Chiu TTW, Poon ATK. The relationship between head posture and severity and disability of patients with neck pain. Man Ther. 2008; 13:148-154.

8. Guimarães I. A Ciência e a Arte da Voz Humana. Alcabideche, Portugal: ESSA; 2007.

9. Roussouly P, Nnadi C. Sagittal plane deformity: an overview of interpretation and management. Eur Spine J. 2010;19:1824-1836.

10. Angsuwarangsee T, Morrison M. Extrinsic laryngeal muscular tension in patients with voice disorders. J Voice. 2002;16:333-343.

11. Roy N, Bless DM. Personality traits and psychological factors in voice pathology: a foundation for future research. J Speech Lang Hear Res. 2000; 43:737-748.

12. Van Houtte E, Claeys S, D'Haeseleer E, Wuyts F, Van Lierde K. An examination of surface EMG for the assessment of muscle tension dysphonia. $J$ Voice. 2013;27:177-186.

13. Verdolini K, Rosen CA, Branski RC. Classification Manual for Voice Disorder-I. Mahwah, NJ: Erlbaum; 2006.

14. Morrison MD, Rammage LA, Nichol H. Management of the Voice and Its Disorders. 2nd ed. San Diego, CA: Singular; 2001.

15. Harris T, Lieberman J. The cricothyroid mechanism, its relation to vocal fatigue and vocal dysfunction. Voice Forum. 1993;2:89-96.

16. Kooijman PGC, de Jong FICRS, Oudes MJ, Huinck W, Van Acht H, Graamans K. Muscular tension and body posture in relation to voice handicap and voice quality in teachers with persistent voice complaints. Folia Phoniatr Logop. 2005;57:134-147.

17. Rubin JS, Lieberman J, Harris TM. Laryngeal manipulation. Otolaryngol Clin North Am. 2000;33:1017-1034

18. Rubin JS, Blake E, Mathieson L. Musculoskeletal patterns in patients with voice disorders. J Voice. 2007;21:477-484.

19. Arboleda BMW, Frederick AL. Considerations for maintenance of postural alignment for voice production. J Voice. 2006;22:90-99.

20. Wilson EL, Madigan ML, Davidson BS, Nussbaum MA. Postural strategy changes with fatigue of the lumbar extensor muscles. Gait Posture. 2005; 23:348-354.

21. Hamaoui A, Do Mc, Poupard L, Bouisset S. Does respiration perturb body balance more in chronic low back pain subjects than in healthy subjects? Clin Biomech. 2002;17:548-550.

22. Cuccia A, Caradonna C. The relationship between the stomatognatic system and body posture. Clinics. 2009;64:61-66.

23. Bruno E, Padova A, Napolitano B, Marroni P, Batelli R, Ottaviani F, Alessandrini M. Voice disorders and posturography: variables to define the success of rehabilitative treatment. J Voice. 2009;23:71-75.

24. MacIntyre NJ, Bennett L, Bonnyman AM, Stratford PW. Optimizing reliability of digital inclinometer and flexicurve ruler measures of spine curvatures in postmenopausal women with osteoporosis of the spine: an illustration of the use of generalizability theory. ISRN Rheumatol. 2011;2011:571698.

25. Greendale GA, Nili NS, Huang MH, Seeger L, Karlamangla AS. The reliability and validity of three non-radiological measures of thoracic kyphosis and their relations to the standing radiological Cobb angle. Osteoporos Int. 2011;22:1897-1905.

26. Guimarães I, Abberton E. Fundamental frequency in speakers of Portuguese for different voice samples. $J$ Voice. 2005;19:592-606.

27. Hirano M. Clinical Examination of Voice. New York, NY: Springer Verlag; 1981.

28. Behlau M, Madazio G, Feijó D, Pontes P. Avaliação da voz. In: Behlau M, ed. org. Voz: O Livro do EspecialistaVol. I. Rio de Janeiro, Brasil: Revinter; 2001:85-245.

29. Mendes A, Castro E. Acoustic analysis of voice assessment: phonatory tasks and acoustic parameters. Rev Port ORL. 2005;43:127-136.

30. Yiu E, Worrall L, Longland J, Mitchell C. Analyzing vocal quality of connected speech using Kay's computerized speech lab: a preliminary finding. Clin Linguist Phon. 2000;14:295-305. 
31. Brutha T, Patrick L, Garnett JD. Perceptual evaluation of voice quality and its correlation with acoustic measurements. $J$ Voice. 2004;18:299-304.

32. Ortega J, Cassinello N, Dorcaratto D, Leopaldi E. Computerized acoustic voice analysis and subjective scaled evaluation of the voice can avoid the need for laryngoscopy after thyroid surgery. Surgery. 2009;145:265-271.

33. IBM Corp. Released. IBM SPSS Statistics for Windows, Version 20.0. Armonk, NY: IBM Corp; 2011.

34. Cohen J. Statistical Power Analysis for the Behavioral Sciences. 2nd ed. Hillsdale, NJ: Lawrence Erlbaum Associates; 1988.

35. Wang HJ, Giambini H, Zhang WJ, et al. A modified sagittal spine posture classification and its relationship to deformities and spinal mobility in a Chinese osteoporotic population. PLoS One. 2012;7:e38560.

36. Van Royen BJ, Toussaint HM, Kingma I, Bot SD, Caspers M, Harlaar J, Wuisman PI. Accuracy of the sagittal vertical axis in a standing lateral radiograph as a measurement of balance in spinal deformities. Eur Spine J. 1998;7:408-412.

37. Miyakoshi N, Itoi E, Kobayashi M, Kodama H. Impact of postural deformities and spinal mobility on quality of life in postmenopausal osteoporosis. Osteoporos Int. 2003;14:1007-1012.

38. Bricot B. Posturologia. São Paulo, Brasil: Ícone Editora; 1999.

39. Giovanni A, Akl L, Ouaknine M. Postural dynamics and vocal effort: preliminary experimental analysis. Folia Phoniatr Logop. 2008;60:80-85.

40. Morrison MD, Rammage LA. Muscle misuse voice disorders: description and classification. Acta Otolaryngol. 1993;113:428-434.

41. Liebermen J. Principles and techniques of manual therapy: applications in the management of dysphonia. In: Harris T, Harris S, Rubin JS, Howard DM, eds. The Voice Clinic Handbook. London, UK: Whurr; 1998:91-138.

42. Hulse M. Zerzikale dysphonic. Folia Phoniatr Logop. 1991;43:181-196.

43. Estenne M, Zocchi L, Ward M, Macklem Pt. Chest wall motion and expiratory muscle use during phonation in normal humans. J Appl Physiol. 1990;68:2075-2082.

44. Hoit JD, Palssman BL, Lansing RW, Hixon TJ. Abdominal muscle activity during speech production. J Appl Physiol. 1988;65:2656-2664.

45. Hoit JD. Influence of body position on breathing and its implications for the evaluation and treatment of speech and voice disorders. $J$ Voice. 1995;9: 341-347.

46. Cavallo SA, Baken RJ. Prephonatory laryngeal and chest wall dynamics. $J$ Speech Hear Res. 1985;28:79-87.

47. Iwarsson J, Sundberg J. Effects of lung volume on vertical larynx position during phonation. J Voice. 1998;12:159-165.

48. Fedorak C, Ashworth N, Marshall J, Paull H. Reliability of the visual assessment of cervical and lumbar lordosis: how good are we? Spine. 2003;28:1857-1859.

49. Quek J, Pua YH, Clark RA, Bryant AL. Effects of thoracic kyphosis and forward head posture on cervical range of motion in older adults. Man Ther. 2013;18:65-71.

50. Roussouly P, Gollogly S, Berthonnaud E, Dimnet J. Classification of the normal variation in the sagittal alignment of the human lumbar spine and pelvis in the standing position. Spine. 2005;30:346-353.

51. Guimarães I. An Electrolaryngographic Study of Dysphonic Portuguese Speakers [unpublished $\mathrm{PhD}$ dissertation]. London, UK: University of London; 2002

52. Boersma P, Weenink D. PRAAT: Doing phonetics by computer, Version 5.3. 23. Amsterdam, The Netherlands: University of Amsterdam; 2012.

53. Sataloff R. Clinical Assessment of Voice. San Diego, CA: Plural Publishing; 2005.

\section{ADDENDUM}

\section{Postural evaluation}

\section{Sagittal photographs}

Each participant underwent photographs in a standing position, in the sagittal view, for visualization of spinal curvatures. A Sony digital camera (Sony Cyber-Shot DSC-W350, Sony Corporation, Tokyo, Japan) was used to take the photographs, keeping the same distance for all participants. Clothing covering the back was removed to ensure accurate identification of bony landmarks. Footwear was also removed for a consistent standing posture. Subjects were oriented to stand in an erect position and to maintain their natural posture throughout the procedure. ${ }^{9,48,49}$

\section{Postural analysis}

To analyze the photographs, the Digimizer program (MedCalc Software Ltd, Ostend, Belgium) was used. It allowed us to increase the image countless times, for greater accuracy in analyzing and marking, without quality loss. Also it allowed, using a reference with known dimension in the photograph, to take subsequent measurements in centimers, of points marked on the image. The methodology followed was that used in the Flexicurve method, where a vertical line was drawn to connect the $\mathrm{C} 7$ landmark (point A in Figure 1) and the L5/S1 interspace landmark (point $\mathrm{C}$ in Figure 1). ${ }^{24}$ In our study, this analysis was made digitally, using the photograph and the Digimizer program (MedCalc Software Ltd, Ostend, Belgium). The conventional methods for determining the thoracic and lumbar curvature based on thoraco-lumbar junction are simplistic, so we considered the change in the spatial relationship between the vertebral bodies, called the inflection point. ${ }^{9,50}$ This is represented in Figure 1 as point $\mathrm{B}$. The TL was measured in centimeters from $\mathrm{C} 7$ (point $\mathrm{A}$ ) and the inflection point (point B). The LL was measured in centimeters from the inflection point (point B) and L5/S1 interspace (point C). The value 0.00 in the LL means that the distance between point $\mathrm{B}$ and $\mathrm{C}$ is null. There is no point of inflection (point B) and lumbar curvature is flat. A kyphotic attitude is maintained along the entire spinal column (A to C). Thoracic width (TW) was the vertical distance from the straight line to the point of the greatest thoracic curvature (point D in Figure 1). KI was then determined using the equation $\mathrm{KI}=\mathrm{TW} / \mathrm{TL} \times 100$. For a measure to be clinically useful, it must have a sufficiently high ICC and a sufficiently low standard error of measurement (SEM) ${ }^{19}$ The intrarater reliability evaluated through the ICC, presented values that could be classified from good to excellent for all the dependent variables measured. For the KI, the attained value was consistent with the previous finding of Greendale et $\mathrm{al}^{25}$ (ICC $\geq 0.9$ ). The SEM varied from 0.440 to 1.215. No literature was found describing the reliability of measures of spine curvatures in normal and dysphonic speakers using the Digimizer and digital Flexicurve.

\section{Voice quality evaluation}

\section{Voice recordings}

The acoustic signal was obtained by a Marantz PMD660 (Kanagawa, Japan) with a Beyerdynamic unidirectional headset, in a Faraday Cage. The microphone was positioned lateral to the mouth, keeping a constant distance of $5 \mathrm{~cm}$ for all subjects. During recordings, speakers were standing in their usual posture, as natural as possible, in an acoustic level which was not masked by postural adaptations. The vocal behaviors performed were the European Portuguese sustained vowels [u], [i], and [a], which correspond to the extreme positions of the vowel 
phonetic system, as well as conversation and reading (Portuguese version of "The story of Arthur the rat" $\left.{ }^{51}\right)$. Perceptiveauditory voice analysis was done by an Speech and Language Therapist (SLT) — the principal researcher.

\section{Perceptual and acoustical assessment}

Perceptively, the GRBAS scale ${ }^{27}$ was adopted to classify subjects on the basis of the presence of dysphonia. A speaker was classified as dysphonic when he/she obtained a score $\geq 1$ in the Grade component of the GRBAS scale. Roughness, breathiness, aesthenia and strain components were quality parameters and were not considered in the normal versus dysphonic classification. Acoustically, fundamental frequency, jitter, intensity, shimmer, and harmonic-to-noise ration (HNR) were the five variables considered for the normal versus dysphonic groups' decision. Praat software (v5.3.23, Amsterdam, The Netherlands; Boersma and Weenink ${ }^{52}$ ) was used and acoustic measurements were obtained in an automatic form from the signal portion selected ( 1.5 seconds), which represents mean values. For the sustained vowel analysis, only the medial portion was considered, which corresponds to the more stable signal portion. Jitter, shimmer, and HNR values were not considered in the analysis of sequential speech. ${ }^{8,51}$

\section{Ear, nose, and throat assessment}

The ear, nose, and throat speaking voice analysis was based on the laryngeal examination proposed by Sataloff. ${ }^{53}$ During the assessment of the voice phenomena, nasoendoscopy was used to obtain the most natural speech behavior and it also allowed the assessment of the upper airways, crucial for voice quality. Furthermore, during nasoendoscopy, recordings were performed with the sustained [i] phonation with increasing frequency, standardized sentences, and quiet breathing. 